\title{
Nonalcoholic Fatty Liver Disease and the Risk of Atrial Fibrillation
}

\author{
Mahmoud A. Abou Omar ${ }^{1}$, Ahmed Alaarag ${ }^{1}$, Sherief Abd-Elsalam ${ }^{2 *}$, Mohamed El-Abgeegy ${ }^{3}$, Rehab Ahmed ${ }^{3}$, \\ Ahmed Abdelhaleem Mohamed ${ }^{3}$, Mahmoud Khalil ${ }^{3}$, Yousry Esam-Eldin Abo-Amer ${ }^{4}$, Mahmoud Elkadeem $^{2}$, Mohamed Yousef $^{2}$ \\ ${ }^{1}$ Department of Cardiology, Tanta University, Tanta, Egypt; ${ }^{2}$ Department of Tropical Medicine, Tanta University, Tanta, Egypt; \\ ${ }^{3}$ Department of Hepatology, Tropical Medicine and Infectious Diseases, National Hepatology and Tropical Medicine Research \\ Institute, Cairo, Egypt; ${ }^{4}$ Department of Hepatology, Gastroenterology and Infectious Diseases, Mahala Hepatology Teaching \\ Hospital, Gharbia, Egypt
}

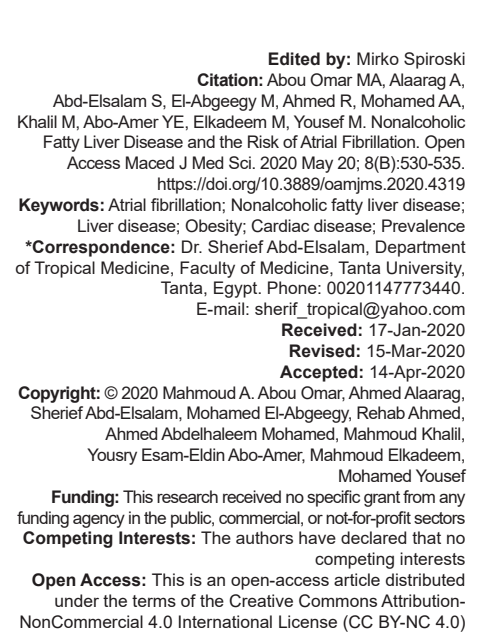

\begin{abstract}
BACKGROUND: Nonalcoholic fatty liver disease (NAFLD) is now the factor behind the development of liver cirrhosis, liver cell failure, and liver transplantation in many cases. However, its relation to atrial fibrillation (AF) could not be cleared up.

AIM: The purpose of the study was to evaluate prevalence of AF in the setting of NAFLD; the association between them, and to evaluate risk factors of AF in this category of patients.

METHODS: This cross-sectional study was performed on 400 patients between January 2018 and June 2019. These patients were analyzed for the presence of NAFLD and presence of persistent or chronic AF.

RESULTS: There were 138 patients with NAFLD, and 20 patients with persistent or permanent AF. Factors associated with AF were old age, male gender, and high values of aspartate aminotransferase, alanine-aminotransferase, $\gamma$-glutamyltranspeptidase, and serum uric acid. The participants with AF had a significantly greater prevalence of NAFLD than those without AF.

CONCLUSION: Incidence and prevalence of atrial fibrillation in NAFLD patients were high. Severity of liver disease
\end{abstract} was an important predictor of new-onset atrial fibrillation.

\section{Introduction}

Liver disease has an impact on autonomic nervous system through affecting circulating inflammatory peptides. This effect creates a proarrhythmic status [1], [2], [3], [4]. Autonomic dysfunction and inflammation seems to have a role in the development of atrial fibrillation (AF) [5].

There are few studies about AF in liver diseases, and these studied did not assess the severity of liver disease [6], [7], [8].

The prevalence of nonalcoholic fatty liver disease (NAFLD) could not be known accurately because of its variability in different people including age, gender, ethnicity, and various concomitant diseases. In addition, the different methods of NAFLD detection, including liver enzyme, imaging analysis (i.e., ultrasound or magnetic resonance imaging), and histological analysis make accurate detection of the prevalence too hard. Younossi et al., 2018 [8] performed a meta-analysis, showing that $30-35 \%$ of adult NorthAmericans had NAFLD (as detected by ultrasonography), 20-30\% [9], [10] of Europeans and the Middle Easterners had NAFLD, and the prevalence of NALFD among the Chinese and Japanese was from 15 to $30 \%$ and 20 to $30 \%$, respectively [11], [12]. For Indian subcontinent populations, the prevalence was from $16 \%$ to $32 \%$ [13].

It is clear that the prevalence of NAFLD is much higher in special groups of populations (i.e., patients with dyslipidemia T2DM, obesity, or hypertension) [3], [14], NASH prevalence was reported to be from $30 \%$ to $70 \%$ in Type II DM population-based studies and from $45 \%$ to $75 \%$ in large hospital-based studies [14].

AF is the most common supraventricular arrhythmia seen in clinical practice in spite of improvement in management of cardiovascular disorders [15].

Käräjämäki et al., 2016 [16] detected independent association between NAFLD and high incidence of AF. This study aimed to evaluate prevalence of AF in the setting of NAFLD; the association between them and to evaluate risk factors of AF in this category of patients. 


\section{Methods}

This cross-sectional study included 400 patients who were received in outpatient clinics in the Cardiology and Hepatology Departments in a major university hospital in the period from January 2018 until June 2019 after taking consent from every one. The study protocol was reviewed and approved by the Ethics Committee (at Tanta Faculty of Medicine). All patients were informed and agreed to share in the study. Patients whose alcoholic history was unknown or known to be excessive alcoholic were excluded from the study.

Clinical examinations, including anthropometric and laboratory measurements, were performed. Weight and height were measured with basic clothing after shoes removal. Body mass index (BMI) was calculated (Wt $[\mathrm{kg}] /$ height $\left.^{2}\left[\mathrm{~m}^{2}\right]\right)$. Blood pressure was measured by sphygmomanometer in a sitting position. Fasting plasma glucose (FPG), triglycerides (TG), total cholesterol (TC), high-density lipoprotein (HDL), low-density lipoprotein (LDL), alanine aminotransferase (ALT), aspartate aminotransferase (AST), $\gamma$-glutamyltranspeptidase (GGT), serum uric acid, and albumin were measured using antecubital vein fasting blood samples. All values were measured using an Olympus AU640 autoanalyzer (Olympus, Kobe, Japan) and standard methods.

Diagnosis of NAFLD was based according to abdominal ultrasonography performed by well-trained operators who were blind to the laboratory and clinical data, and after excluding other etiology. The apparatus used was a Toshiba Nemio 20 sonography machine with a 3.5-MHz probe (Toshiba, Tokyo, Japan) [15].

Diagnostic criteria of fatty liver included: (1) Increased liver brightness; (2) diffuse hyperechogenicity of the liver compared to the kidneys; (3) deep attenuation of hepatic echo; and (4) intrahepatic vessel borders and diaphragm [16]. This study used ultrasonography also for evaluation of intra-abdominal organs (liver, spleen gallbladder, and pancreas).

AF was diagnosed using a 12-lead electrocardiogram (ECG) showing irregularly irregular ventricular rate and absent discrete $P$ waves.

\section{Statistical analysis}

The collected data were tabulated and statistically analyzed using Prism 5 software statistical computer package version 5. Range, mean, standard deviation, number, and percent were calculated. Chisquare and Fisher exact test were used as a test of significance. Continuous variables between the two groups were compared with the t-test. $p<0.05$ was considered significance.

\section{Results}

Clinical characteristics of the included patients: Of the 400 participants included in this study, 138 met the diagnostic criteria for NAFLD (34.5\%, 98 males and 40 females). Of the entire sample, 20 participants $(5.0 \%$, 16 males and 4 females) had persistent or permanent AF. The clinical characteristics of patients are shown in Table 1. Patients with AF were older, more likely to be male, and had significantly higher values of AST, ALT, GGT, serum uric acid. BMI, blood pressure, lipid profile, albumin, and FPG did not significantly differ between the two groups. As shown in Table 1, the participants

Table 1: Baseline clinical, demographic, and characteristics of studied patients stratified by AF status

\begin{tabular}{llllll}
\hline Characteristic & All pts $(\mathrm{n}=400)$ & $\begin{array}{l}\text { Pts without AF } \\
(\mathrm{n}=380)\end{array}$ & $\begin{array}{l}\text { Pts with AF } \\
(\mathrm{n}=20)\end{array}$ & t value & $\mathrm{p}$ value \\
\hline Age (years): & $60.5 \pm 9.2$ & $59.2 \pm 8.0$ & $64.6 \pm 9.5$ & 2.015 & 0.0093 \\
Mean \pm SD & & & & & \\
Gender, No. & $291 / 109$ & $276 / 104$ & $16 / 4$ & 2.08 & 0.08 \\
(M/F) & & & & & \\
BMI (kg/m) & $24.90 \pm 2.70$ & $23.60 \pm 3.00$ & $23.70 \pm 2.80$ & 0.145 & 0.88 \\
Systolic BP & $135.10 \pm 15.00$ & $134.30 \pm 15.10$ & $136.10 \pm 14.60$ & 0.520 & 0.60 \\
Diastolic BP & $73.40 \pm 11.60$ & $72.60 \pm 11.80$ & $73.40 \pm 12.10$ & 0.292 & 0.768 \\
FPG (mg/dl) & $108.50 \pm 12.30$ & $110.40 \pm 11.90$ & $105.8 \pm 12.70$ & 1.67 & 0.09 \\
Total chol. (mg) & $176.50 \pm 19.80$ & $175.40 \pm 19.60$ & $165.50 \pm 20.70$ & 1.28 & 0.198 \\
HDL (mg/dl & $40.96 \pm 4.58$ & $40.26 \pm 4.64$ & $38.64 \pm 3.70$ & 1.53 & 0.125 \\
LDL (mg/dl) & $131.65 \pm 19.50$ & $130.60 \pm 19.20$ & $128.50 \pm 18.90$ & 0.477 & 0.633 \\
TG (mg/dl) & $164.50 \pm 22.10$ & $162.70 \pm 21.0$ & $157.30 \pm 19.80$ & 1.124 & 0.260 \\
AST (U/L) & $32.10 \pm 3.72$ & $31.80 \pm 3.70$ & $33.90 \pm 3.91$ & 2.40 & 0.014 \\
ALT (U/L) & $24.82 \pm 3.94$ & $24.50 \pm 3.90$ & $26.30 \pm 4.10$ & 2.01 & 0.045 \\
$\gamma$-GTP (U/L) & $22.49 \pm 3.60$ & $22.41 \pm 3.50$ & $24.20 \pm 4.00$ & 2.20 & 0.0275 \\
Albumin(g/L) & $44.83 \pm 2.80$ & $44.54 \pm 2.70$ & $45.28 \pm 2.90$ & 1.190 & 0.234 \\
Serum UA & $5.23 \pm 1.64$ & $5.10 \pm 1.60$ & $5.90 \pm 2.85$ & 2.33 & 0.020 \\
(mg/dL) & & & & & \\
NAFLD (\%) & 33.4 & 33.2 & 44.4 & & \\
\hline AST:Asp & & &
\end{tabular}

AST: Aspartate aminotransferase, ALT: Alanine aminotransferase, GTP: Glutamyltranspeptidase,

LDL: Low-density lipoprotein, HDL: High-density lipoprotein, FPG: Fasting plasma glucose, TG: Triglycerides, BMI: Body mass index, M/F: Male/female, BP: Blood pressure, AF: Atrial fibrillation, NAFLD: Nonalcoholic fatty liver disease.

with AF had a significantly greater prevalence of NAFLD than those without AF. As regards NAFLD status (Table 2), the group of NAFLD contained more males and was slightly older than the group without NAFLD. The values for SBP, DBP, BMI, LDL, TG, AST, ALT, GGT, FPG, albumin, and serum UA were higher among the participants with NAFLD; but, they had lower values of HDL. Furthermore, as shown in Table 2, there was a marked difference in the prevalence of AF among participants with or without NAFLD.

Table 2: Baseline clinical, demographic, and characteristics of studied patients stratified by NAFLD status

\begin{tabular}{lllll}
\hline Characteristic & $\begin{array}{l}\text { Pts without NAFLD } \\
(\mathrm{n}=272)\end{array}$ & $\begin{array}{l}\text { Pts with NAFLD } \\
(\mathrm{n}=138)\end{array}$ & $\mathrm{t}$ value & $\mathrm{p}$ value \\
\hline Age (years): Mean \pm SD & $61.20 \pm 8.80$ & $62.20 \pm 8.60$ & 1.09 & 0.273 \\
Gender, No. (M/F) & $170 / 102$ & $98 / 40$ & 1.4 & 0.294 \\
BMI (kg/m) & $24.00 \pm 2.800$ & $23.90 \pm 2.90$ & 0.337 & 0.7358 \\
Systolic BP & $133.40 \pm 16.80$ & $138.20 \pm 18.30$ & 2.82 & 0.005 \\
Diastolic BP & $72.70 \pm 12.00$ & $75.90 \pm 11.80$ & 2.56 & 0.0106 \\
FPG (mg/dl) & $112.30 \pm 11.80$ & $118.40 \pm 13.20$ & 4.6 & 0.001 \\
Total chol. (mg) & $154.30 \pm 12.40$ & $160.25 \pm 11.60$ & 1.32 & 0.203 \\
HDL (mg/dl & $42.20 \pm 6.40$ & $38.10 \pm 4.6$ & 6.534 & 0.001 \\
LDL (mg/dl) & $120.40 \pm 17.80$ & $126.20 \pm 19.30$ & 3.03 & 0.0026 \\
TG (mg/dl) & $150.20 \pm 22.80$ & $170.30 \pm 26.8$ & 2.30 & 0.025 \\
AST (U/L) & $28.60 \pm 4.60$ & $32.10 \pm 5.8$ & 6.60 & 0.0013 \\
ALT (U/L) & $24.80 \pm 3.40$ & $30.20 \pm 3.80$ & 4.58 & 0.001 \\
$\gamma$-GTP (U/L) & $21.400 \pm 2.800$ & $24.60 \pm 4.10$ & 9.20 & 0.001 \\
Albumin(g/L) & $44.500 \pm 2.900$ & $46.20 \pm 2.60$ & 1.41 & 0.150 \\
Serum UA (mg/dL) & $5.00 \pm 2.100$ & $5.6 \pm 3.00$ & 2.23 & 0.019 \\
AF (\%) & 2.1 & 3.8 & & \\
\hline AST: Aspartate aminotransferase, AST: Aspartate aminotransferase, ALT: Alanine aminotransferase,
\end{tabular}

GTP: Glutamyltranspeptidase, LDL: Low-density lipoprotein, HDL: High-density lipoprotein, FPG: Fasting plasma glucose, TG: Triglycerides, BMI: Body mass index, M/F: Male/female, BP: Blood pressure, AF: Atrial fibrillation 
The association between AF and NAFLD remained statistically significant even after adjustment for age and gender. Further adjustment for SBP, FPG, GGT, HDL, and TG did not remarkably change the study group's status. Age and GGT were independent predictors of AF.

AST and ALT were calculated according to normal values up to $45 \mathrm{U} / \mathrm{L}$. GGT was calculated with the upper limit $50 \mathrm{U} / \mathrm{L}$ for males and $32 \mathrm{U} / \mathrm{L}$ for females. There was an increasing trend of the prevalence rate of AF as serum liver enzyme increased. The prevalence rates of AF in normal and elevated serum AST groups were $2.1 \%$ and $9.8 \%(p<0.001)$. The rates in normal and elevated serum ALT groups were $2.0 \%$ and $8.2 \%$ ( $p=0.003$ ). Meanwhile, the rates in GGT groups were $1.7 \%$ and $7.8 \%$ with significant result as well $(p<0.001)$. These results showed that participants with higher serum liver enzyme are more likely to develop AF than those with lower one.

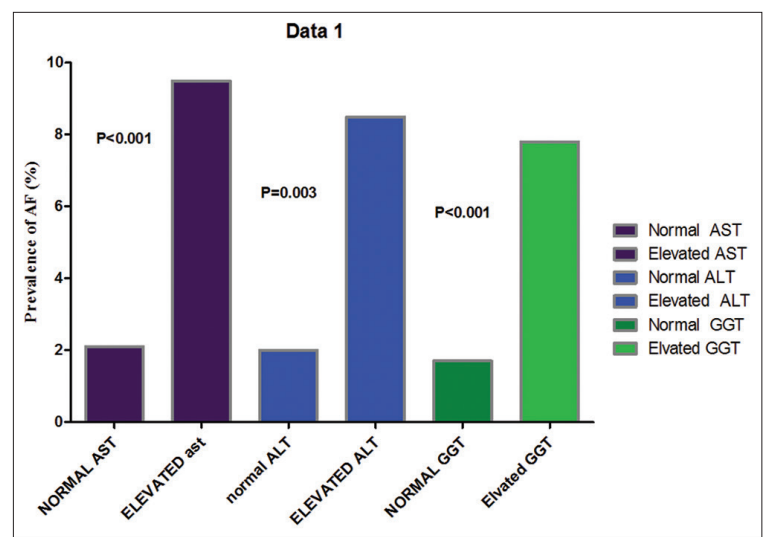

Figure 1: Prevalence of atrial fibrillation in patients stratified by normal or elevated serum liver enzyme concentration

As regards the relationship between NAFLD and AF, participants were classified into three groups: Group without NAFLD, group with NAFLD and normal AST/ALT/GGT, and group with NAFLD and elevated AST/ALT/GGT. AF was significantly higher among patients with elevated liver enzymes; also, in those with hepatic steatosis, irrespective of liver enzymes. However, the presence of AF among those without hepatic steatosis on ultrasound was not significant (Figures 1 and 2).

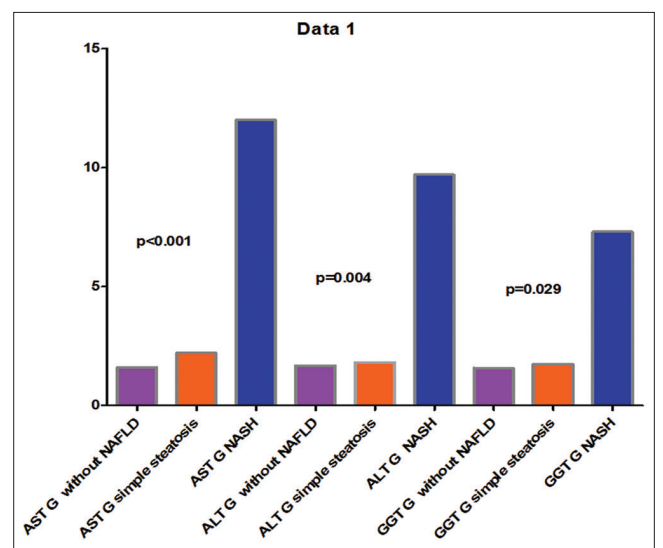

Figure 2: Prevalence of atrial fibrillation in patients stratified by nonalcoholic fatty liver disease status on ultrasound combined with normal or elevated serum aspartate aminotransferase/alanine aminotransferase $/ \gamma$-glutamyltranspeptidase concentration

\section{Discussion}

Till now, multiple similar risk factors can lead to both AF and NAFLD. As a result, there were many studies about the association between AF and NAFLD [17], [18], [19], [20], [21]. However, they were limited. A study made by Targher et al. [20] was restricted on subjects with type II diabetes mellitus and the OPERA study focused on middle-aged patients [16].

AF is prevalent in patients with liver disease. Furthermore, incidence of AF is proportional to the severity of liver disease, which is independently associated with new-onset $A F$, in spite of adjustment of other AF risk factors. This finding may explain additional mechanistic insight into the pathogenesis of AF, which shares the underlying link of inflammation and autonomic dysfunction, known to play a role in development of AF. Both cardiologists and hepatologists consider AF screening in patients with liver disease [21], [22], [23].

Our study revealed the association between NAFLD and AF. The serum transaminase levels were significantly associated with high risk of AF. It is not known whether the association between them is causative relationships or these two diseases share common pathophysiologic mechanisms. As it is reasonable to deduce that there may be a causal link between them because NAFLD is known to be a risk factor for many cardiovascular diseases.

Our finding could be explained by the following: First, liver transaminases may link NAFLD and AF which was in agreement with The Framingham Heart Study which detected the independent relationship between liver transaminase concentrations and the risk of new-onset AF in the general adult population [24]. Targher et al.'s [18] study detected that GGT was the only liver enzyme significantly associated with the prevalence of AF in Type II diabetes patients [18]. A similar result was found in our studied patients. GGT is also a systemic marker of NAFLD so that the development of the two diseases may be parallel. Furthermore, it has been proven that the most specific marker of liver pathology (ALT) is also associated with an increased risk of cardiovascular-related mortality [25], [26], [27], [28], [29].

As regards AST, it is produced in the both liver and myocardium, increases in either NAFLD or AF patients, or in patients with both conditions. This is similar to our results. Therefore, control of liver transaminase concentrations may have a role in reduction of the mortality in patients with $A F$.

Second, NAFLD leads to accumulation of lipids in the liver, impaired lipoprotein metabolism, increased oxidative stress, and release of inflammatory factors [30], which are important risk factors for 
AF [32], [33], [34]. Furthermore, it was reported that AF could trigger inflammatory environment [33], creating a vicious cycle.

Persistent low levels of LDL and HDL cause further lipoprotein consumption [31]. These conclusions were consistent with our results where HDL cholesterol, LDL cholesterol, and TG were all lower in group with AF than in the group without AF.

Third, since NAFLD carries multiple cardiovascular complications, it may induce AF direct through several mechanisms including left ventricular diastolic dysfunction [35], and alteration of atrial conduction properties [36]. Fat does not accumulate only in the liver tissue but also in other organs and viscera including cardiac tissue (myocardium, pericardium, and atrial septum) so that the diastolic function of the atria or the ventricle, and electrical activity may be affected [36], [37].

Finally, many studies have reported that NAFLD is an independent risk factor for autonomic dysfunction [38], [39], [40] which has a role in development of AF [40], [41].

There were some limitations to our study. First, NAFLD was not diagnosed histologically but though ultrasound which was non-invasive and cost-effective. Second, the sample was small. Third, AF was diagnosed according to resting ECG without $24 \mathrm{~h}$ dynamic ECG which was more precise but more difficult. Fourth, the cross-sectional nature of our study did not enable us to know the most recent mean levels of some lab results of every patient. As formal cohort studies have shown, NAFLD is associated with an increased risk of prevalent AF [18], [19], [42].

\section{Conclusion}

NAFLD is an independent risk factor for AF mainly with the progression of liver disease. NAFLD patients should be examined for arrhythmia symptoms, and evaluated ECGs and ambulatory monitors. Future studies are needed to evaluate risks and benefits of anticoagulation in the setting of liver disease.

\section{Acknowledgments}

The authors acknowledge all patients participated in this study and take responsibility for all aspects of the reliability and freedom from bias of the data presented and their discussed interpretation.

\section{References}

1. Dumcke CW, Moller S. Autonomic dysfunction in cirrhosis and portal hypertension. Scand J Clin Lab Invest. 2008;68(6):43747. https://doi.org/10.1080/00365510701813096 PMid:18609092

2. Rangari M, Sinha S, Kapoor D, Mohan JC, Sarin SK. Prevalence of autonomic dysfunction in cirrhotic and noncirrhotic portal hypertension. Am J Gastroenterol. 2002;97(3):707-13. https:// doi.org/10.1111/j.1572-0241.2002.05551.x

PMid:11922567

3. Voigt MD, Trey G, Levitt NS, Raine R, Lombard CJ, Robson SC Gordon G, Kirsch RE. Autonomic neuropathy in extra-hepatic portal vein thrombosis: Evidence for impaired autonomic reflex arc. J Hepatol. 1997;26(3):634-41. https://doi.org/10.1016/ s0168-8278(97)80430-8

PMid:9075672

4. Patel $\mathrm{P}$, Dokainish $\mathrm{H}$, Tsai $\mathrm{P}$, Lakkis $\mathrm{N}$. Update on the association of inflammation and atrial fibrillation J CardiovascElectrophysiol. 2010;21(9):1064-70. https://doi. org/10.1111/j.1540-8167.2010.01774.x PMid:20455973

5. Chen PS, Chen LS, Fishbein MC, Lin SF, Nattel S. Role of the autonomic nervous system in atrial fibrillation: Pathophysiology and therapy. Circ Res. 2014;114(9):1500-15. https://doi. org/10.1161/circresaha.114.303772

PMid:24763467

6. Lee H, Choi EK, Rhee TM, Lee SR, Lim WH, Kang SH, et al. Cirrhosis is a risk factor for atrial fibrillation: A nationwide, population-based study. Liver Int. 2017;37(11):1660-7. https:// doi.org/10.1111/liv.13459

PMid:28432810

7. Mwalitsa JP, Maimone S, Filomia R, Alibrandi A, Saitta C Caccamo G, et al. Atrial fibrillation in patients with cirrhosis. Liver Int. 2016;36(3):395-400. https://doi.org/10.1111/liv.12928 PMid:26235424

8. Younossi ZM, Koenig AB, Abdelatif D, Fazel Y, Henry L, Wymer M. Global epidemiology of nonalcoholic fatty liver disease-Meta-analytic assessment of prevalence, incidence, and outcomes. Hepatology. 2016;64(1):73-84. https://doi. org/10.1002/hep.28431

PMid:26707365

9. Loomba R, Sanyal AJ. The global NAFLD epidemic. Nat Rev Gastroenterol Hepatol. 2013;10(11):686-90. https://doi. org/10.1038/nrgastro.2013.171

PMid:24042449

10. Fan JG, Jia JD, Li YM, Wang BY, Lu LG, Shi JP, et al. Guidelines for the diagnosis and management of nonalcoholic fatty liver disease: update 2010: (Published in Chinese on Chinese Journal of Hepatology 2010;18:163-166. J Dig Dis. 2011;12(1):38-44. https://doi.org/10.1111/j.1751-2980.2010.00476.x

PMid:21276207

11. Farrell GC, Wong VW, Chitturi S. NAFLD in Asia as common and important as in the West. Nat Rev Gastroenterol Hepatol. 2013;10(5):307-18. https://doi.org/10.1038/nrgastro.2013.34 PMid:23458891

12. Das K, Das K, Mukherjee PS, Ghosh A, Ghosh S, Mridha AR, et al. Non obese population in a developing country has a high prevalence of nonalcoholic fatty liver and significant liver disease. Hepatology. 2010;51(5):1593-602. https://doi. org/10.1002/hep.23567

PMid:20222092

13. Singh SP, Nayak S, Swain M, Rout N, Mallik RN, Agrawal O, 
et al. Prevalence of nonalcoholic fatty liver disease in coastal eastern India: A preliminary ultrasonographic survey. Trop Gastroenterol. 2004;25(2):76-9.

\section{PMid:15471321}

14. Targher G, Byrne CD. Clinical review: Nonalcoholic fatty liver disease: A novel cardiometabolic risk factor for Type 2 diabetes and its complications. J Clin Endocrinol Metab. 2013;98(2):48395. https://doi.org/10.1210/jc.2012-3093

PMid:23293330

15. Rahman F, Kwan GF, Benjamin EJ. Global epidemiology of atrial fibrillation. Nat Rev Cardiol. 2014;11(11):639-54. https:// doi.org/10.1038/nrcardio.2014.118

PMid:25113750

16. Käräjämäki $A J$, Pätsi $O P$, Savolainen $M$, Kesäniemi $Y A$, Huikuri $H$, Ukkola $O$. Non-alcoholic fatty liver disease as a predictor of atrial fibrillation in middle-aged population (OPERA study). PLoS One. 2015;10(11):e0142937. https://doi. org/10.1371/journal.pone.0142937

PMid:26571029

17. Targher G, Mantovani A, Pichiri I, Rigolon R, Dauriz M, Zoppini G, et al. Non-alcoholic fatty liver disease is associated with an increased prevalence of atrial fibrillation in hospitalized patients with Type 2 diabetes. Clin Sci. 2013;125(6):301-9. https://doi.org/10.1042/cs20130036 PMid:23596966

18. Targher G, Valbusa F, Bonapace S, Rigolon R, Dauriz M, Zoppini G, et al. Non-alcoholic fatty liver disease is associated with an increased incidence of atrial fibrillation in patients with Type 2 diabetes. PLoS One. 2013;8(2):e57183. https://doi. org/10.1371/journal.pone.0057183 PMid:23451184

19. Markus MR, Meffert PJ, Baumeister SE, Lieb W, Siewert U, Schipf S, et al. Association between hepatic steatosis and serum liver enzyme levels with atrial fibrillation in the general population. The study of health in Pomerania (SHIP). Atherosclerosis. 2016;245:123-31. https://doi.org/10.1016/j. atherosclerosis.2015.12.023

PMid:26722832

20. Targher G, Bertolini L, Poli F, Rodella S, Scala L, Tessari R, et al. Nonalcoholic fatty liver disease and risk of future cardiovascular events among Type 2 diabetic patients. Diabetes. 2005;54(12):3541-6. https://doi.org/10.2337/ diabetes.54.12.3541

PMid:16306373

21. Zhou Y, Lai C, Peng C, Chen M, Li B, Wang X, et al. Non alcoholic fatty liver disease as a predictor of atrial fibrillation: A systematic review and meta-analysis. Postępy Kardiol Interwencyjnej. 2017;13(3):250-7. https://doi.org/10.5114/aic.2017.70198 PMid:29056998

22. Ding YH, Ma Y, Qian LY, Xu Q, Wang LH, Huang DS, et al. Linking atrial fibrillation with non-alcoholic fatty liver disease: Potential common therapeutic targets. Oncotarget. 2017;8(36):60673-83. https://doi.org/10.18632/oncotarget.19522

PMid:28948002

23. Wijarnpreecha $\mathrm{K}$, Boonpheng $\mathrm{B}$, Thongprayoon $\mathrm{C}$, Jaruvongvanich $\mathrm{V}$, Ungprasert $\mathrm{P}$. The association between nonalcoholic fatty liver disease and atrial fibrillation: Ametaanalysis. Clin Res Hepatol Gastroenterol. 2017;41(5):52532. https://doi.org/10.1016/j.clinre.2017.08.001 PMid:28866089

24. Sinner MF, Wang N, Fox CS, Fontes JD, Rienstra M, Magnani JW, et al. Relation of circulating liver transaminase concentrations to risk of new-onset atrial fibrillation. Am J Cardiol. 2013;111(2):21924. https://doi.org/10.1016/j.amjcard.2012.09.021

PMid:23127690
25. Ong JP, Pitts A, Younossi ZM. Increased overall mortality and liver-related mortality in non-alcoholic fatty liverdisease. J Hepatol. 2008;49(4):608-12. https://doi.org/10.1016/j. jhep.2008.06.018

PMid:18682312

26. Söderberg C, Stål P, Askling J, Glaumann H, Lindberg G Marmur J, et al. Decreased survival of subjects with elevated liver function tests during a 28-year follow-up. Hepatology. 2010;51(2):595-602. https://doi.org/10.1002/hep.23314

27. Ioannou GN, Weiss NS, Boyko EJ, Mozaffarian D, Lee SP. Elevated serum alanine aminotransferase activity and calculated risk of coronary heart disease in the United States. Hepatology. 2006;43(5):1145-51. https://doi.org/10.1002/hep.21171 PMid:16628637

28. Abdelmoemen G, Khodeir SA, Zaki AN, Kassab M, Abou-Saif S, Abd-Elsalam S. Overexpression of hepassocin in diabetic patients with nonalcoholic fatty liver disease may facilitate increased hepatic lipid accumulation. Endocr Metab Immune Disord Drug Targets. 2019;19(2):185-8. https://doi.org/10.2174/ 1871530318666180716100543 PMid:30009716

29. Wasfy E, Elkassas G, Elnawasany S, Elkasrawy K, AbdElsalam S, Soliman S, et al. Predicting esophageal varices in cirrhotic hepatitis $C$ virus patients using noninvasive measurement of insulin resistance variables. Endocr Metab Immune Disord Drug Targets. 2018;18(6):573-80. https://doi.org $/ 10.2174 / 1871530318666180803120428$ PMid:30073932

30. Furukawa S, Fujita T, Shimabukuro M, Iwaki M, Yamada Y, Nakajima $Y$, et al. Increased oxidative stress in obesity and its impact on metabolic syndrome. J Clin Invest. 2004;114(12):175261. https://doi.org/10.1172/jci21625

PMid:15599400

31. Ndumele CE, Nasir K, Conceic RD, Carvalho JA, Blumenthal RS, Santos RD. Hepatic steatosis, obesity, and the metabolic syndrome are independently and additively associated with increased systemic inflammation. Arterioscler Thromb Vasc Biol. 2011;31(8):1927-32. https://doi.org/10.1161/ atvbaha.111.228262

PMid:21546603

32. Harada M, VanWagoner DR, Nattel S. Role of inflammation in atrial fibrillation pathophysiology and management. Circ J. 2015;79(3):495-502. https://doi.org/10.1253/circj.cj-15-0138 PMid:25746525

33. Guo Y, Lip GY, Apostolakis S. Inflammation in atrial fibrillation. J Am Coll Cardiol. 2012;60(22):2263-70. https://doi. org/10.1016/j.jacc.2012.04.063

PMid:23194937

34. Hanafy AS, Seleem WM, El-Kalla F, Basha MA, AbdElsalam S, et al. Efficacy of a non-invasive model in predicting the cardiovascular morbidity and histological severity in non-alcoholic fatty liver disease. Diabetes Metab Syndr 2019;13(3):2272-8. https://doi.org/10.1016/j.dsx.2019.05.032 PMid:31235168

35. Rijzewijk LJ, van der Meer RW, Smit JW, Diamant M, Bax JJ, Hammer S, et al. Myocardial steatosis is an independent predictor of diastolic dysfunction in Type 2 diabetes mellitus. J Am Coll Cardiol. 2008;52(22):1793-9. https://doi.org/10.1016/j. jacc.2008.07.062 PMid:19022158

36. Ozveren O, Izgi C, Eroglu E, Simsek MA, TurerA, KucukdurmazZ, et al. Doppler tissue evaluation of atrial conduction properties in patients with non-alcoholic fatty-liver disease. Ultrason Imaging 2015;38(3):225-35. https://doi.org/10.1177/0161734615595015 PMid:26157039 
37. Fox CS, Gona P, Hoffmann U, Porter SA, Salton CJ, Massaro JM, et al. Pericardial fat, intra thoracic fat, and measures of left ventricular structure and function. Circulation. 2009;119(12):1586-91. https://doi.org/10.1161/ circulationaha.108.828970

PMid:19289634

38. Chen PS, Turker I. Epicardial adipose tissue and neural mechanisms of atrial fibrillation. Circ Arrhythm Electrophysiol. 2012;5(4):618-20. https://doi.org/10.1161/circep.112.974956 PMid:22895598

39. Newton JL, Pairman J, Wilton K, Jones DE, Day C. Fatigue and autonomic dysfunction in non-alcoholic fatty liver disease. Clin Auton Res. 2009;19(6):319-26. https://doi.org/10.1007/ s10286-009-0031-4

\section{PMid:19768633}

40. Liu YC, Hung CS, Wu YW, Lee YC, Lin YH, Lin C, et al. Influence of non alcoholic fatty liver disease on autonomic changes evaluated by the time domain, frequency domain, and symbolic dynamics of heart rate variability. PLoS One. 2013;8(4):e61803. https://doi.org/10.1371/journal.pone.0061803

PMid:23626730

41. Park HW, Shen MJ, Fishbein MC, Chen LS, Chen PS Neural mechanisms of atrial fibrillation. Curr Opin Cardiol. 2012;27(1):24-8.

PMid:22139702

42. Trivedi I, Rinella ME. NAFLD and cardiovascular disease: Can the real association be determined? Curr Hepatitis Rep. 2014;13(2):130-41. https://doi.org/10.1007/s11901 -014-0231-9 